\title{
Methods and techniques of research objects of forensic building-technical expertise (FBTE)
}

\author{
Svetlana Kolobova ${ }^{1, *}$ \\ ${ }^{1}$ Moscow State University of Civil Engineering, 129337 Yaroslavskoe sh. 26, Moscow, Russia
}

\begin{abstract}
This article discusses classical and modern methods and techniques of scientific and expert study objects of forensic buildingtechnical expertise; dialectical peculiarities and logical methods of interdisciplinary methods, special scientific methods used in certain circumstances to establish causal linkages. Examples of their practical application. Is denoted by the prospect of the development of new methods and techniques of research to improve the quality of judicial construction and technical expertise.
\end{abstract}

\section{Introduction}

Forensic building-technical expertise (FBTE) remains very popular among different kind of expertise. The court considered the claims of multimillion-dollar construction companies and mostly from expert opinion depends on the court decision. Hence the importance of choosing the right experts, methodologies and methods of research facilities construction expertise.

Russian scientists R.S. Belkin, A.I. Winberg and N.T. Malahovskya, N.A. Selivanov, A.R. Shlyakhov, E.R. Rossinskaya and others $[1,2,3,4,5]$ were at the beginnings of the creation of expert methodology. Scientists have developed a classification of the different methods used when conducting expert studies. R.S. Belkin, E.R. Rossinskaya have developed three-tier system proposed methods: universal dialectic method-shared (scientific) methods are special methods of science.

A.I. Winberg and A.R. Shlyakhov [6] substantiated scientific method system and expert study, taking into account their degree of commonality and subordination. This system can be represented as follows:

1. Universal dialectic method and methods of logic;

2. General (scientific) methods: observation, measurement, description, planning, experiment, simulation, etc., are used in many branches of science and practice;

3. Special methods, originally developed for a certain kind of (species) examination or borrowed from other areas of scientific or application activities.

The experts shall be guided by the following well known in their research methods.

\footnotetext{
${ }^{*}$ Corresponding author: KolobovaSV@mgsu.ru
} 


\section{The dialectical method}

The methodological basis for all research involves the use of public and private research methods, idiosyncratic methods and techniques that depend on a particular task, the subject and object of research "[7]. the main logical methods include analysis, synthesis, abstraction, generalization of idealization, deduction, induction, analogy, extrapolation, modeling, hypothesis [8].

Determination methods and research of causality formulated in the early 17 th century, $f$. Bacon, in the 19th century systematized and refined D.S. Mill. Hence their name: "the canons (principles) Bacon-Mill", in modern editions-"methods of Bacon-Mill", described in handbooks and instructional editions according to the logic of [9].

Similarity Method and the only difference method for singular method differences based on experiment, unlike the only similarity, which is based on observation.

For example, in the study of building collapse experienced by you can set the following:

-engineering survey errors and survey errors;

-errors of designers for loads on structures, strength

and the quality of the material;

-unfavorable reasons, reducing the quality and durability of materials and structures in the process of transportation, storage, installation, etc.;

-third-party effects (rain, wind, an abrupt change in temperature) and internal factors (breaking the rules) on the quality of the material.

For the conclusion about the cause of the events change, on the one hand, strength parameters of material, on the other hand, appearance, character and magnitude of load, carry out two experiments, one of which analyzed event occurs and the other not. These two cases are related in all circumstances, except one, which is present only in the first of them. The second case is a result of the Elimination of the circumstances. If such a removal will disappear and the phenomenon itself, the repaired fact can be considered a prerequisite for building structure collapse occurred.

While conducting experiments, including instrumental studies, it should be borne in mind that many construction materials are not homogeneous in content. That is evident in the construction sites, with long periods of operation, as well as subjected to intensive aggressive Wednesday. So, the characteristics of the same material, measured in different parts of the same design (for example, staying in the underground and above-ground parts) can vary widely in their numerical value.

The combined method of differences and similarities : If two or more cases when this phenomenon occurs, similar in only one circumstance, whereas two or more cases occur in the absence of this phenomenon and are distinguished only by the fact that this circumstance does not exist, then this circumstance, and there is probably a reason the phenomenon. This method applies when there is no possibility of an accurate accounting of the composition and nature of the circumstances leading up to the event being investigated, that there was a need in the separate use of similarities and differences.

Method of accompanying changes used when changing one changes and other phenomena, and other circumstances remain unchanged, i.e. between these phenomena a causal relationship exists. This method applies when modeling expert Builder process, consisting of a large number of components having different origins. For example, destruction of building structures may be linked to the violation of technology of building production.

Application of the method of residues when correctly identify clear disproportion causes investigated actions. If the activity in scope, scale or intensity does not match a known reason, the question of the existence of any other circumstances. 
According to E.K. Voishvillo and M.G. Degtyarev: "If the cause of a phenomenon is not among some aggregate of previous circumstances, it must be among other prior circumstances or perhaps, among the circumstances that were in this case even unrecorded» [10].

Often the results can occur under the influence of more than one (particular) causes a number of reasons, acting independently (multiple reasons). For example, the causes of destruction of constructions buildings can be defects in steel structures, inaccurate installation (dock) details, process preparation of solutions.

"Because of the multiplicity of causes, says A.A. Eisenman, a" competition reasons "[11]. As a result of this "competition" "WINS" (expert) one or more of the number alleged.

The complexity of the method consists in choosing a single true cause of many. Causes may be the lack of special measuring instruments, testing base, inadequate and incomplete initial data, as from the date of the event that occurred, for example, collapse of building, pending a court decision on the FBTE time goes by. Then it is not one, but two or more possible causes that may have only an indicative value for the Court.

Unlike the multiplicity of causes mixing of consequence (action) occurs when the target event could occur only as a result of the joint impact of not one, but two or more factors. Each of them serves as a prerequisite for the coming result, but not a sufficient condition.

\section{General (scientific) methods}

These include sensuous-rational methods. Life phenomena must be understood not just as a set of separate, isolated elements, but as their set of systemized in a certain way [12]. Expert Builder studies most often uses such methods as surveillance, comparison or analogy relations and analogy items.

In FBTE is the most common method of graphic simulation. A graphical model is floor plans of buildings and constructions, land plans, case plans, etc. as a means of fixing the results of observations and measurements obtained by the expert. The need for building graphical models occurs in court cases about the legality of buildings, real estate section, share allocation, recognition of the right of ownership of building objects. In graphical models reflect the most significant for the proper dispute resolution characteristics of objects: orientation to the sides of the beam, the configuration and dimensions of the plot, the arrangement of residential and ancillary buildings and their location relative to the boundaries of the land, engineering networks and other communications, the availability of green spaces. Created by expert graphic models are required by an application expert elicitation and important evidential, supporting the conclusions.

Method of idealization is the establishment and exploration of ideal, mentally constructed objects. The value of this method to FBTE due to the specificity of its objects and the nature of the tasks performed by an expert. Real estate objects attached to land may not be presented directly to the expert. So their study is completed in two stages. In the first phase the expert fixes the basic characteristics of the objects relevant to the case. The second phase occurs mediated perception of the object when the material and symbolic information is converted to an ideal. Analyzing sketches, drawings, records, results measurement, expert "complements" the perfect image of investigated them in kind of object parts, which together with the already etched in the memory of moments create a system of signs, which gives an idea of the object's properties to solve other tasks in search of an answer to a question put by the Court. Using the method of formalization of concepts are replaced with special symbols and characters. The method is also used in the preparation of expert opinions. The examiner should give explanations in detention indicate that means one or another character (symbol), or it may be significantly more difficult. This 
method allows you to visually assess the results of the work carried out to all actors of the judicial process.

The second group of interdisciplinary methods-mathematical methods involving measurement, calculations and geometric building. When investigating a plot of land or a building complex configuration expert can produce about 100 measurements, allowing it later graphically reproduced in a certain scale positioning located on station buildings and structures or premises. Measurements shall be made on a number of occasions, either manually, by using a measuring tape and using the latest laser and optical measuring instruments, where it is technically feasible. Results are processed error and used to justify the withdrawal.

In any study of the applied computing. So calculated the cost and volume of completed and outstanding construction, construction and repair, commissioning, operation and durability of bearing and enclosing structures of buildings, constructions and buildings, etc.

The following General scientific periodical method-geometric build. Environment establishes the location of the object's sketchy plan. The plan gives a clear view on the mutual arrangement of items, various signs of investigated objects detected during inspection.

Now increasingly apply cybernetic methods that can help in many cases to meet the study objectives. Used linear programming methods. When determining the volume of excavation is used with success in computing, which helps determine the execution of mass haul volumes on a computing machine with vertical planning areas, for example, with a balance of zero.

Dynamic programming methods give possibility to choose the optimal ways of movement of construction machinery or best route construction machinery at the construction site, taking into account natural obstacles in the terrain, the shape of the construction site, wear of machines, their mobility and speed, fuel consumption and other indicators.

When construction of the facility shall develop schedules for different technological models that satisfy certain requirements, important of which is to match the managed object model, i.e. the criteria. Each of the models has the most appropriate scope. For example, the mission with the image stream in its development in time and space are most convenient when scheduling the construction of multistory and single-storey model buildings and structures.

Network models to accurately reflect the order of erection of a complex object, give reasoned decisions in the case of changing situations in the course of erection of the object. Especially efficient alternative network models with variable structure and enable you to display multiple variants perform the same process.

Successfully used in FBTE such as information systems (AIS) "House" AIS "Earth", developed by Members of the forensic expert institution of the Ministry of justice of Russia.

Modern information technology based on their use, let you search and automated processing of scientific, technical, legal and statistical information needed for the production of FBTE; produce in the course of research computation and mathematical modeling, as well as computer simulation in choosing, for example, a typical expert versions or reconstruction elements of the situation before, at the time and after the events, which became subject to investigation or prosecution.

\section{Special scientific methods or special methods}

Their application is limited to one or a few scientists or industries applied activities. 
The most common research methods in FBTE are physical, chemical, physical-chemical for analysis of morphology, composition, structure, and properties of substances and materials used in the construction industry; methods for extrajudicial investigations. Using these methods, an expert Builder can determine the cause of the collapse of building structures, deformation etc.

In FBTE are used as proven methods, old and modern, using high-tech equipment.

Methods developed for extrajudicial investigations:

-establish the causes and conditions of the collapse of construction objects, determine their status and opportunities of reconstruction;

-verification of the characteristics and properties of products manufacture of building materials and products, and their compliance with these technical passports and certificates; -determination of physical and technical characteristics of local building materials;

-selection of concretes, mortars, mastics, anti-corrosion and other construction formulations;

-sampling of soil, concrete and mortar;

-manufacturing of samples and testing (including weld joints); -determination of concrete strength in structures by non-destructive methods and products.

A special place among the special methods of photographing method takes, as has a high degree of clarity, accuracy and completeness of the transmission conditions.

Research methods in FBTE can be divided into reproductive and heuristic. Reproductive, in turn, are subdivided into qualitative-descriptive and algorithmic, suggesting a certain set and sequence of operations expert.. Algorithmic methods are different from qualitative-descriptive in a strict sequence of actions. Under the Granovsky G.L. algorithm refers to exactly formulated a rule whose purpose is to be a guide for achieving the desired result [13].

Heuristic methods, in contrast to algorithmic and qualitative-descriptive compliance do not provide for a specific sequence of actions. Heuristic decision is considered to be found in the production process of examination by the expert himself [14] or when such use existing techniques, which selectively ignores a number of its provisions. Following the selected version, he "jumps" through the methodology stages (for example, verification of the opposite version), complements her new elements and study substantiates the results obtained. Heuristic methods are based on creative thinking and intuition expert, based on experience. The application of these methods has its limits. They can only be used at certain stages of the study, and the decision of the expert tasks cannot be based on heuristics.

Reasonable combination of classical and modern methods used by the Builder during the examination, such as dialectical and logical methods, scientific methods, including various modeling techniques: graphical simulation, cybernetic methods including mathematical and computer modeling will successfully meet the challenges FBTE and answer the questions of the Court, having worked on techniques and methods for material.

The inevitable technological advances in construction is happening rapidly, new building materials, innovative technologies and high-tech devices. Therefore, the term and the emergence of new methodological approaches to the study of objects FBTE.

Methodical recommendations on study of objects FBTE.

Depending on the nature of the task or tasks the experts choose certain methods, which are divided into generic (generic), generic and specific (private).

Generic (specific) expert technique is applied to a certain type of expertise. For FBTE it is more expedient to use the generic and not specific techniques. Each specific technique will aim to solve cluster close to its content. Among others, raises questions about the amount and cost of actually executed works, including the quality, on the quantity and market value of the construction works for the Elimination of deficiencies and defects of poorly executed works. This content is determined by the setting of trial, resolution of 
which requires the use of special expert knowledge-Builder, for example: the need for a decision by the Court of the question of the use of the building after the fire, whether the reconstruction and further exploitation, establish the cost of repair and reconstruction works in apartments (other areas), damaged the Bay (fire) [15].

The typical technique is popular or common tasks without any adaptation. The structure model of the methodology consists of the following elements:

-a description of the typical events that become the subject of legal proceedings;

-list of objects;

-methods and means of research;

-provisions concerning the sequence of conditions and procedures for the application of methods and tools;

-assumptions about the possible outcome of the use of methods and means; the characteristic of these results in terms of expert tasks.

Specific (private) technique is designed to address a particular (private) expert task. During the creation of specific individual elements of the methodology by the expert model methods are ignored and it is supplemented by new elements. As a result of expert based on the model technique and its knowledge develops methodology for each of its subtasks, as well as the program of study for this situation. The structure of a particular methodology is a way to study the combination of working methods or individual techniques and funds research.

Currently, a number of publications released [Borodina E.A. Butyrina A.Y. Davydenko O.V. Malysheva S.D. Popova A.N., etc.], which identified methodological approaches to research forensic examiner-Builder, such approaches are detailed, the choice of certain methods and means is justified. So far, however, has not yet created any official methodical system to tackle all challenges FBTE. This will be achieved on a particular, higher stage of development expertise of this kind. The absence of such a system, however, does not mean the impossibility of formalizing common tasks FBTE, develop algorithms to solve them. The need to update the Foundation and development of forensic FBTE methods in their writings of reputable scientists.

In the future it is necessary to consider that inevitable scientific progress in construction is happening rapidly, new building materials, innovative technologies and high-tech devices. Therefore it is inevitable and the emergence of new methodological approaches and methods of the study.

Reasonable combination of classical and modern techniques and methodologies used by the expert Builder during the examination, such as dialectical and logical methods, scientific methods, including various modeling techniques: graphical simulation, cybernetic methods including mathematical and computer modeling will successfully meet the challenges FBTE and answer the questions of the Court, having worked on techniques and methods for material.

The inevitable technological advances in construction is happening rapidly, new building materials, innovative technologies and high-tech devices. Therefore, in the long term the emergence of new methodological approaches and methods of the study.

So, you will need the following tools and methodological recommendations: nullify construction sites to the category of movable and immovable property; by definition, construction projects in the categories of capital or non-capital; establish opportunities and develop options for a real section of public and industrial buildings between their owners; to establish the functional purpose of basement and attic residential apartment buildings; to establish the causes, conditions, circumstances and destruction mechanism of the construction site [16].

With the development of modern construction technologies, both domestic and foreign, imported into our country, objects of FBTE have become complex multifunctional 
complexes, industrial and civil buildings and structures, as well as large-scale plots, functionally related. Among these objects could meet the tall buildings and unique constructions. In such cutting-edge objects space-planning and design as construction sites in General and their individual fragments, innovative building materials, designs, products, technical equipment, etc. All of the above was the development of the judicial buildingtechnical expertise, and it required new methodological approaches and techniques. [16]

\section{Conclusions}

Formation of methodic base basic judicial construction and technological research can be conventionally passes through three stages. In the first phase, experts, receiving questions the Court will divide them into questions that can be answered by applying the technique of production expertise of a certain type and subspecies (private technique) [17] and on the remaining issues that need to be answered by applying a specific methodology study [18]. In the future a specific technique can be adapted to the new object of study. The first phase can last for a long time [19] to the need to address the qualitatively new expert tasks. Next, in the second phase, experts share experience in publications of articles of scientific and methodical nature of the reports at scientific conferences, in describing the emerging practice solutions expert tasks not covered previously in the literature. Conducted the peer review of the study of regularities expressed would trigger the development of new methodological approaches and techniques. In articles subjective expert opinion contrasted with emerging trends in practice, solving the tasks stated and disclosed their insolvency or difficulty, outlines the proper from the point of view of the authors, the system methods which provides science-based result [20].

The third stage of methodological framework includes preparation, approval, publication and implementation procedures (guidelines) forensic solutions to common challenges. In the system of forensic science institutions of adoption procedures (guidelines) is carried out by the scientific-methodical Council of experts under Ministry of justice of Russia. This three-tier structure of the process of formation of forensic of methodic base FBTE allows you to organize your modern methodical development of forensic experts-Builders according to the degree of development of their separate directions.

The past in October 2015 years Kazakhstan international legal forum "development of forensic expertise in the context of the Eurasian Economic Union» brought together participants of the modern court proceedings in an effort to transition to a qualitatively new level of forensic technology. Currently, the ways of upgrading expertise in Eurasia, such as standardization, accreditation, certification, validation and inter-laboratory proficiency testing. One of the priority directions for development of the Eurasian Economic Union is the coordination of scientific-methodical work, improving the provision of information, the development of new hi-tech investigation techniques [21].

Close regional and international cooperation will lead to the development of new effective methods and methodical recommendations of FBTE and hence improve the quality of forensic evidence.

\section{References}

1. R.S. Belkin, Experimental method of obtaining samples for comparative studies (Moscow, 1961)

2. A.I. Winberg, N.T. Malahovskaya, Trial expertology (theoretical and methodological problems of forensic examinations) (Volgograd, 1979) 
3. N.A. Selivanov, Controversial forensic issues (Moscow, 1978)

4. A.R. Shlyakhov. Actual problems of theory of forensic expertiseVNIISÈ, 33-49 (1984)

5. E.R. Rossinskaya, Forensics in criminal, civil, arbitration process (Norm, Moscow, 2006)

6. A.I. Winberg, A.R. Shlyakhov, General doctrine of forensic methods, 54-94 (1977)

7. A.I. Winberg, A.R. Shlyakho, General doctrine of forensic methods, 65 (1977)

8. N.I. Kondakov, Logical (Moscow, 1975)

9. E.K. Voishvillo, M.G. Degtyarev, Logic, 143-150, 273, 149-152, 293, 34 (2000)

10. E.K. Voishvillo, M.G. Degtyarev, Logic, (Moscow, 2000)

11. A.A. Eisenman, Expert opinion (structure and scientific justification) (Moscow, 1967)

12. The foundations of scientific knowledge for lawyers: Stud. for universities (Moscow, 1999)

13. G.L. Granovsky, Expert tasks and their solutions in the light of the STC, 42, 27-44 (1980)

14. G.1. Granovsky, Mikrotrasologičeskih Research Methods (VNIISÈ, Moscow, 1983)

15. A.Yu. Butyrin, O.V. Lukovkina, Methodology expert solution to the question of the cost of repair apartments. Damaged Gulf (fire), 55-175 (2007)

16. E.B. Stativa,). Russian Federal Centre for forensic sciences under the Ministry of Justice of the Russian Federation, 4(36), 72-78 (2014)

17. Y.G. Koruhov, Dictionary of basic terms of legal expertis. (Moscow, 2007)

18. The specific technique is the technique of manufacturing expertise in a particular case (see ibid., p. 44)

19. Expert production no. 823/19-3, no. 3456/19-2. Archive of experts under Ministry of justice of Russia, (2013, 2014)

20. A.Yu. Butyrin, Principles divisibility criteria for real stuff and a section of the building sites of various functional purposes, Theory and practice of forensic examination, 1(29), 75-80 (2013)

21. A.I. Usov, Law and State, 1(70), 48-52 (2016) 